\title{
Juvenile Idiopathic Arthritis
}

\author{
Kenan Barut, Amra Adrovic, Sezgin Şahin, Özgür Kasapçopur
}

Department of Pediatric Rheumatology, İstanbul University Cerrahpaşa Medical School, İstanbul, Turkey

Juvenile idiopathic arthritis is the most common chronic rheumatic disease of unknown aetiology in childhood and predominantly presents with peripheral arthritis. The disease is divided into several subgroups, according to demographic characteristics, clinical features, treatment modalities and disease prognosis. Systemic juvenile idiopathic arthritis, which is one of the most frequent disease subtypes, is characterized by recurrent fever and rash. Oligoarticular juvenile idiopathic arthritis, common among young female patients, is usually accompanied by anti-nuclear antibodie positivity and anterior uveitis. Seropositive polyarticular juvenile idiopathic arthritis, an analogue of adult rheumatoid arthritis, is seen in less than $10 \%$ of paediatric patients. Seronegative polyarticular juvenile idiopathic arthritis, an entity more specific for childhood, appears with widespread large- and small-joint involvement. Enthesitis-related arthritis is a separate disease subtype, characterized by enthesitis and asymmetric lower-extremity arthritis. This disease subtype represents the childhood form of adult spondyloarthropathies, with human leukocyte antigen-B27 positivity and uveitis but commonly without axial skeleton involvement. Juvenile psoriatic arthritis is characterized by a psoriatic rash, accompanied by arthritis, nail pitting and dactylitis. Disease complications can vary from growth retardation and osteoporosis secondary to treatment and disease activity, to life-threatening macrophage activation syndrome with multi-organ insufficiency. With the advent of new therapeutics over the past 15 years, there has been a marked improvement in juvenile idiopathic arthritis treatment and long-term outcome, without any sequelae. The treatment of juvenile idiopathic arthritis patients involves teamwork, including an experienced paediatric rheumatologist, an ophthalmologist, an orthopaedist, a paediatric psychiatrist and a physiotherapist. The primary goals of treatment are to eliminate active disease, to normalize joint function, to preserve normal growth and to prevent long-term joint damage. Timely and aggressive treatment is important to provide early disease control. The first-line treatment includes disease-modifying anti-rheumatic drugs (methotrexate, sulphasalazine, leflunomide) in combination with corticosteroids, used in different dosages and routes (oral, intravenous, intraarticular). Intra-articular application of steroids seems to be an effective treatment modality, especially in monoarthritis. Biological agents should be added in the treatment of unresponsive patients. Anti-tumour necrosis factor agents (etanercept, infliximab, adalimumab), anti-interleukin-1 agents (anakinra, canakinumab), antiinterleukin-6 agents (tocilizumab) and T-cell regulatory agents (abatacept) have been shown to be safe and effective in childhood patients. Recent studies reported sustained reduction in joint damage with even complete clinical improvement in paediatric patients, compared to previous data.

Keywords: Juvenile idiopathic arthritis, biologic therapy in childhood, pediatric rheumatology, chronic arthritis in childhood

\footnotetext{
Address for Correspondence: Dr. Özgür Kasapçopur, Department of Pediatric Rheumatology, İstanbul University Cerrahpaşa Medical School, İstanbul, Turkey e-mail: ozgurkasapcopur@hotmail.com - ozgurkc@istanbul.edu.tr

Received: 22 January $2017 \quad$ Accepted: 10 February 2017・DOI: 10.4274/balkanmedj.2017.0111

Available at www.balkanmedicaljournal.org

Cite this article as:

Barut K, Adrovic A, Şahin S, Kasapçopur Ö. Juvenile Idiopathic Arthritis. Balkan Med J 2017;34:90-101

${ }^{\circ}$ Copyright 2017 by Trakya University Faculty of Medicine / The Balkan Medical Journal published by Galenos Publishing House.
} 


\section{JUVENILE IDIOPATHIC ARTHRITIS}

Juvenile idiopathic arthritis (JIA) is the most common chronic rheumatic disease in childhood and is of unknown aetiology. JIA encompasses several different subgroups and predominantly presents with peripheral arthritis. The disease spectrum consists of various clinical conditions. Endogenous and exogenous antigens with increased inflammatory response have been shown to play a central role in the pathogenesis of the disease. Chronic inflammation limits the daily activities and productivity of the patient. By definition, disease onset prior to the age of 16 years and arthritis persisting for longer than 6 weeks are required criteria for diagnosis of JIA $(1,2)$. JIA represents a new, common name for several conditions considered separately in the past. Furthermore, similar terms were previously used for the same clinical entity: juvenile rheumatoid arthritis and juvenile chronic arthritis (JCA) (3). The aim of this manuscript is to review the main disease characteristics of, and to update novel therapeutical options for, the most common chronic rheumatic disease in childhood.

\section{Classification}

The International League of Associations for Rheumatology (ILAR) proposed classification criteria for JIA. The last revised criteria, which were updated in 2001, are still widely used.
According to ILAR classification criteria, JIA is divided into seven subtypes: oligoarticular JIA, seropositive polyarticular JIA, seronegative polyarticular JIA, systemic-onset JIA (sJIA), enthesitis-related arthritis (ERA), juvenile psoriatic arthritis (JPsA) and undifferentiated JIA (Table 1) (4). The main criteria of the disease include disease onset prior to the age of 16 and arthritis of at least one joint persisting for longer than 6 weeks with exclusion of any other possible cause of joint inflammation. The disease subtype should be assessed at the onset of the disease and during the follow-up. Initial classification is made according to the clinical features of the first six months in the course of the disease. The onset of new clinical features during the course of the disease determines the final disease subtype (1). The main objective of the disease subclassification is to homogenize the disease groups, define the therapy options, choose the follow-up strategies and predict the disease prognosis.

\section{Epidemiology}

The epidemiological characteristics of the disease are important in order to establish the influence of genetic and environmental factors on the course of the disease. Additionally, they could give a clue as to the correct treatment approach and improve the preventive health-care methods. The prevalence of JIA varies from region to region. Despite the miscellaneous studies on

TABLE 1. International League of Associations for Rheumatology classification of subtypes of juvenile idiopathic arthritis (4)

\begin{tabular}{|c|c|}
\hline Type & Definition and Exclusion $\beta$ \\
\hline Systemic onset JIA & $\begin{array}{l}\text { Fever of } \geq 2 \text { weeks and arthritis in } \geq 1 \text { joint, plus one or more of the following: } \\
\text { 1. Evanescent, non-fixed erythematous rash } \\
\text { 2. Generalized lymph node enlargement } \\
\text { 3. Hepatomegaly, splenomegaly, or both } \\
\text { 4. Serositis } \\
\text { Exclusion: a, b, c, d }\end{array}$ \\
\hline Oligoarthritis onset JIA & Arthritis affecting $\leq 4$ joints during the first 6 months. Exclusion: $a, b, c, d, e$ \\
\hline Persistent oligoarthritis & Affecting $\leq 4$ joints throughout the disease \\
\hline Extended oligoarthritis & Affecting $>4$ joints after the first 6 months \\
\hline Polyarthritis Onset JIA & Arthritis affecting $\geq 5$ joints during the first 6 months \\
\hline Rheumatoid factor negative & RF negative Exclusion: $a, b, c, d, e$ \\
\hline Rheumatoid factor positive & RF positive at least two times 3 months apart Exclusion: $a, b, c, e$ \\
\hline Psoriatic arthritis & $\begin{array}{l}\text { Arthritis and psoriasis or arthritis and at least two of the following: dactylitis, nail pitting or onycholysis, psoriasis in a first- } \\
\text { degree relative Exclusion: b, c, d, e }\end{array}$ \\
\hline Enthesitis-related arthritis & $\begin{array}{l}\text { Arthritis and enthesitis, or arthritis, or enthesitis, with at least two of the following: presence/history of sacroiliac joint } \\
\text { tenderness and/or lumbosacral pain, presence of HLA-B } 27 \text { antigen, onset of arthritis in a male }>6 \text { years old, acute anterior } \\
\text { uveitis. History of one of the following in a first-degree relative: ankylosing spondylitis, enthesitis-related arthritis, } \\
\text { sacroiliitis with inflammatory bowel disease, Reiter syndrome, or acute anterior uveitis } \\
\text { Exclusion: a, d, e }\end{array}$ \\
\hline Undifferentiated arthritis & Fulfils none of the above subsets or fulfils more than one of the above subsets \\
\hline
\end{tabular}

HLA: human leukocyte antigen; RF: rheumatoid factor; JIA: juvenile idiopathic arthritis; $\beta$ exclusion criteria for JIA: (a) psoriasis or a history of psoriasis in the patient or first-degree relative; (b) arthritis in an HLA-B27-positive male beginning after the sixth birthday; (c) ankylosing spondylitis; enthesitis-related arthritis; sacroiliitis with inflammatory bowel disease; Reiter syndrome; or acute uveitis - history of one of these or in first-degree relative; (d) presence of immunuglobin M rheumatoid factor on at least two occasions at least 3 months apart; (e) presence of systemic JIA in the patient 
JIA, the disease prevalence and incidence remain unclear, due to the lack of uniform classification methods and the diversity of disease frequencies in different regions. Data from literature suggest a disease incidence of 1-22 in 100.000 and a disease prevalence of 7-150 in 100.000 (5-7). A study from Turkey reported a prevalence of chronic arthritis in childhood of 64 in 100.000 (8). Interestingly, a study from Australia showed a prevalence as high as 400 in 100.000 (9).

\section{Aetiopathogenesis}

The aetiopathogenesis of the disease is still unclear. The most acceptable theory supports the influence of immunogenic mechanisms secondary to different genetic and environmental factors. Infections, together with stress and trauma, are considered to be the most responsible aetiological factors (6). Gut microbiota is emerging as a relevant factor of autoimmune diseases, including JIA, according to recent studies (10). The increased frequency of autoimmune diseases among JIA patients suggests the genetic basis of the disease (11). Human leukocyte antigen (HLA) B27 and the other HLA tissue types are the most commonly mentioned genetic factors $(3,12-15)$. Various infections are considered to be responsible for JIA pathogenesis: enteric infections, parvovirus B19, rubella, mumps, hepatitis B, Epstein-Barr virus, mycoplasma and chlamydia infections $(2,16)$. Potential trigger-induced T-lymphocytes and secreted cytokines lead to joint destruction. Macrophages, induced by secreted mediators, produce pro-inflammatory cytokines [interleukin (IL) 1, IL-6, tumour necrosis factor (TNF)- $\alpha$ ]. Thus, the acute phase markers [C-reactive protein (CRP), erythrocyte sedimentation rate (ESR)] increase and the acute inflammation of joints occurs with an increase in synovial fluid. Synovial inflammation (synovitis) is characterized by villous hypertrophy and hyperaemia of the subsynovial tissue. Synovial hypertrophy and synovitis secondary to chronic inflammation are known as "panni". The T-lymphocyte percentage in synovial fluids varies among different JIA subtypes, possibly explaining the difference in treatment response among JIA subgroups $(6,7,17)$.

\section{JUVENILE IDIOPATHIC ARTHRITIS SUBTYPES}

\section{Systemic JIA}

This disease subtype, characterized predominantly by systemic symptoms, affects both female and males with the same frequency and may occur at any time during childhood. The presence of arthritis and intermittent fever for at least 2 weeks plus one of the following defines the disease: typical rash, generalized lymphadenopathy, hepatosplenomegaly or serositis. Although its frequency differs between different geographical regions, systemic JIA accounts for $10-20 \%$ of total JIA (6). The temperature rises up to $39.5^{\circ} \mathrm{C}$ once or twice in a day. The intermittent fever is generally accompanied by a typical, salmon pink-coloured rash, which commonly occurs on the trunk and proximal extremities and vanishes with the decline of the fever (Figure 1). Occasionally, polyarticular arthritis, including both large and small joints, may appear during the course of the disease (18). In general, systemic symptoms of fever and rash resolve after the emergence of polyarthritis, which makes distinguishing it from regular polyarticular JIA challenging (3). Fever and other systemic symptoms can persist for months but rarely longer than 6 months. Hepatosplenomegaly and lymphadenopathy are seen in about one-third of patients. Serositis, including pericarditis and pleuritis, may be seen, presenting with marked chest pain. Abdominal pain and myalgia may appear during the peak of the fever $(19,20)$. Leukocytosis, hypochromic microcytic anaemia, thrombocytosis, acute-phase reactant elevation and an increased level of transaminases may be noticed. Elevation of the ferritin level is a relevant issue for sJIA. Auto-antibodies, ANAs and rheumatoid factor (RF) are negative (19). Possible complications of sJIA include osteopenia, osteoporosis, growth retardation, erosive arthritis and amyloidosis. Macrophage activation syndrome (MAS), a severe, life-threatening sJIA complication, is seen in 5-8\% of cases. It is associated with serious morbidity and mortality. Moderate/severe disseminated intravascular coagulation features (thrombocytopenia, increased fibrin degradation products, markedly elevated levels of D-dimers, prolonged prothrombin time and partial thromboplastin time) are present. The ESR drops sharply in association with hypofibrinogenaemia. Typically, liver enzymes, lactate dehydrogenase (LDH), triglycerides and ferritin levels are elevated, sometimes

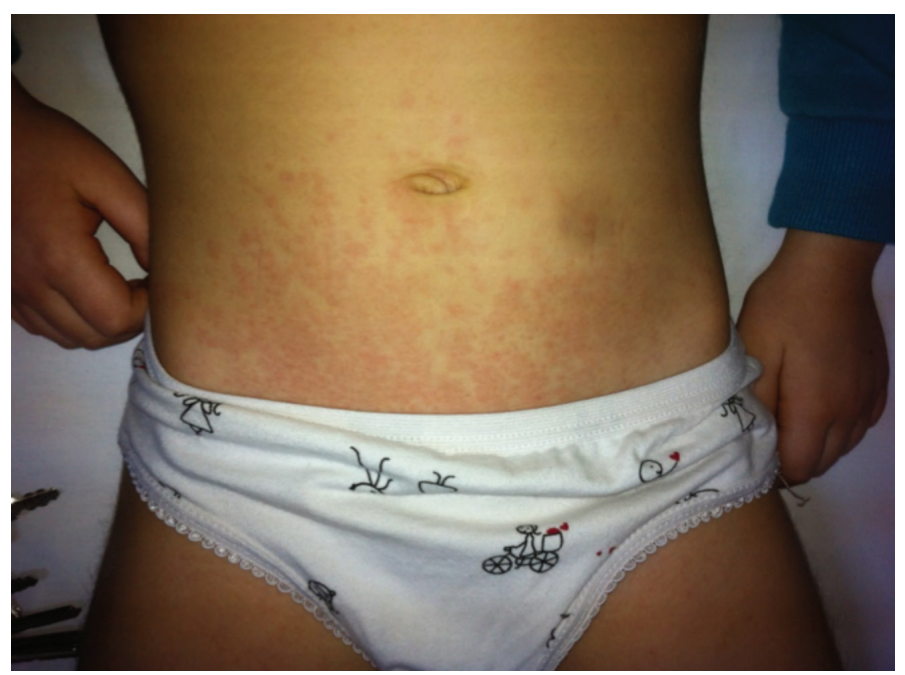

FIG. 1. Typical rash in systemic juvenile idiopathic arthritis. 
with extreme hyperferritinaemia, hypoalbuminaemia and hyponatraemia (21). A European League Against Rheumatism/ American College of Rheumatology/Paediatric Rheumatology International Trials Organisation collaborative initiative recently proposed criteria for MAS complicating systemic JIA: febrile patients with confirmed or suspected sJIA with ferritin $>684 \mathrm{ng} / \mathrm{mL}$ and any two of the following - platelet count $\leq 181 \times 109 / \mathrm{L}$, aspartate aminotransferase $>48$ units $/ \mathrm{L}$, triglycerides $>156 \mathrm{mg} / \mathrm{dL}$, fibrinogen $\leq 360 \mathrm{mg} / \mathrm{dL}$. Although demonstration of prominent haemophagocytosis in the bone marrow aspiration represents a valuable finding, it has not been included in MAS diagnostic criteria since haemophagocytosis cannot be documented in the early stage of MAS (22). The diagnosis of sJIA may be difficult, especially in the early phase of the disease without apparent arthritis. Many conditions should be considered in differential diagnosis of sJIA: infections (septicaemia, bacterial endocarditis, brucellosis, typhoid fever, leishmaniasis, viral infections), malignancies (leukaemia, lymphoma, neuroblastoma), rheumatic fever, connective tissue diseases, Kawasaki disease, Castleman's disease and autoinflammatory diseases (20). Differentiating sJIA at disease onset from Kawasaki disease can be challenging because they have many common clinical and laboratory features, albeit prolonged fever and arthritis are more specific for sJIA (23).

\section{Oligoarticular Juvenile Idiopathic Arthritis}

Oligoarticular JIA is the most common JIA subtype in developed countries, and is generally seen among female patients younger than six (1). It is further subdivided into two subgroups: persistent (no more than four joints affected during the course of the disease) and extended (after the initial 6-month period, the total number of affected joints exceeds four) (4). The RF is negative but the ANA is positive in $70-80 \%$ of patients. Uveitis risk is found to be higher in ANA-positive patients $(5,24)$. Uveitis, rather than arthritis, is the main disability factor in that patient group. Oligoarticular JIA predominantly involves lower-extremity joints, such as the knee and ankle joint. The hip joint is rarely affected. Small-joint involvement is pretty rare in this entity (6). Since small-joint involvement could be an early sign of psoriasis, the family history in particular should be assessed in this group (25). Typically, the disease presents with monoarthritis with an excellent prognosis and without any functional disability. The onset of symptoms could be sudden or insidious. Morning stiffness could present at the onset of the disease and if untreated becomes more prominent in the further course of the disease and even limping could be seen. The affected joint is swollen and often warm, but usually not very painful or tender. These children do not have systemic signs in general $(3,26)$. Laboratory indicators of inflammation may be normal, although mild to moderate elevation of the ESR and CRP levels may occur during the acute phase of the disease. Elevated ESR and arthritis of upper extremities are more common in patients with extended oligoarticular JIA. Mild anaemia and leukocytosis could be seen in patients with acute arthritis $(26,27)$. The disease is characterized by a benign clinical course, in general. However, erosions due to extension to polyarthritis and uveitis are two of the possible severe complications. A significant difference in length between extremities could be seen, depending on the extent of the joint damage. Growth retardation is rare. Although remission is achieved frequently, disease flares may occur many years later; thus, regular follow-up for at least 4-5 years is mandatory (26).

\section{Polyarticular Juvenile Idiopathic Arthritis}

Polyarticular JIA is defined as arthritis of five joints or more during the first 6 months of the disease. The disease is divided into two subgroups, according to RF positivity. The frequency of the disease varies in different geographical regions with the approximate frequency of RF-negative polyarticular JIA being $11-30 \%$ and that of RF-positive being 2-10\% $(6,20,28)$. Both of the disease subgroups are more common among girls. RFnegative polyarticular JIA displays a biphasic trend with peaks of onset between 2 and 4 years and 6 and 12 years. The RF-positive subgroup is more common in later childhood and adolescence (20). Mild fever, weight loss and anaemia are seen in both disease subgroups. Furthermore, moderate hepatosplenomegaly and mild growth retardation could develop (3). Seronegative polyarticular JIA is an entity consisting of three different subgroups. The first one includes an oligoarticular JIA-like condition with the involvement of more than four joints in the first 6 months; the main characteristics of the disease are increased uveitis risk, the development of asymmetric arthritis, early disease onset, female predominance, ANA positivity and association with HLA-DRB1*0801 (20). The second disease subgroup mimics the RF-negative polyarticular JIA with early disease onset, symmetrical involvement of both small and large joints, ANA negativity and variation in disease prognosis. The third disease subtype shows the worst prognosis with poor response to treatment and frequent disease sequelae (20). From time to time, the disease can appear with oligoarticular involvement extending to polyarthritis. The arthritis of the small joints of upper extremities, metacarpal-phalangeal joints and the wrist is typically symmetric (Figure 2). The arthritis of the small joints of lower extremities could be seen, albeit less frequently. Involvement of the hip, cervical spine and shoulder could be seen as well. Temporomandibular arthritis is present in the majority of patients, resulting in secondary microretrognathia $(3,6,29)$. These disease subtypes are associated with a high 
rate of damage, especially hip joint involvement, which is related to high morbidity and surgical interventions (30). Although large-joint involvement could be seen, symmetrical small-joint arthritis is more typical. The clinical course of the RF-positive polyarticular JIA reminds us of adult RA (20). Subcutaneous nodules, histologically similar to nodules seen in RA, could also be seen in RF-positive patients. These nodules spontaneously resolve and are parallel with serum RF levels. Positivity of RF and anti-CCP are the most relevant predictors of significant joint damage (31). Middle anaemia could be documented, due to chronic inflammation in polyarticular JIA patients. Lymphadenopathy and hepatosplenomegaly could accompany the other disease features during the active-disease period. Growth and development retardation may complicate the disease, depending on disease activity. The transaminase level could increase due to disease activity or secondarily to hepatotoxicity of the therapy. The level of transaminases decreases parallel with disease remission (3).

\section{Enthesitis Related Arthritis}

ERA has been one of the most controversial topics in paediatric rheumatology for the last 25 years. These patients show characteristics of both JIA and juvenile spondyloarthropathies. For years, different names were used for the same clinical entity, including type 2 oligoarticular JIA, JCA with late onset, seronegative enthesopathy and arthropathy, arthropathy associated with HLA B27 or juvenile spondyloarthropathy with early onset. The term ERA is defined by Durban classification $(3,4,13)$. The disease is typically seen among males, after the age of six. The main characteristics of the patients include RF and ANA negativity with findings of enthesopathy and asymmetric arthritis of the lower extremities. HLA B27 positivity is reported in $65-80 \%$ of patients (13). Enthesopathy

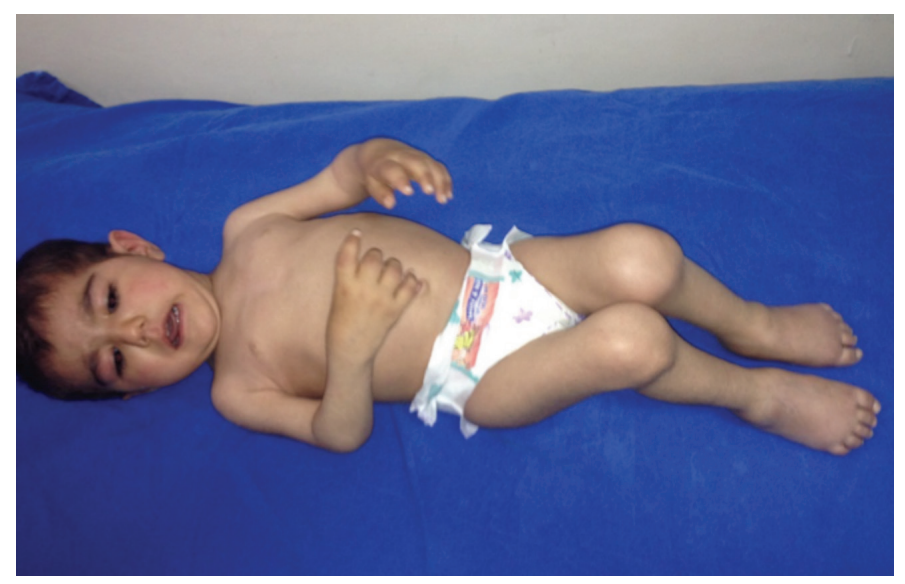

FIG. 2. Widespread joint involvement in polyarticular juvenile idopathic arthritis. represents the inflammation of the attachment sites of the tendons to the bones. Weiss et al. (32) reported enthesopathy in a single site in $47 \%$ and in three different sites in $18 \%$ of patients during the same clinical examination. The Achilles tendon is the most commonly affected site. Patellar insertion of the quadriceps tendon, and calcaneal and metatarsal insertions of the plantar fascia could be affected as well. The affected site is characterized by pain and sensitivity. However, enthesopathy can be seen in different conditions, such as familial Mediterranean fever, Behçet's disease, OsgoodSchlatter syndrome and fibromyalgia $(12,13)$. Typical joint involvement is asymmetric oligoarticular lower-extremity arthritis with the knee and ankle being most commonly affected. It is thought that different infections or traumas could trigger the disease. The most significant distinction from oligoarticular JIA is the involvement of the hip joints. Prolonged arthralgia of the lower extremities could be seen at disease onset. This phase of the disease is not characterized by axial skeleton involvement. The response to non-steroidal anti-inflammatory drugs is excellent with complete or partial remission. The risk of sequelae is low $(12,13)$. However, data from literature show that ineffective treatment in childhood leads to disease progression and the development of ankylosing spondylitis seen among adults. Consequently, early diagnosis and timely treatment represent one of the most relevant topics in paediatric rheumatology (12).

\section{Juvenile Psoriatic Arthritis}

JPsA is still an important topic of discussion in paediatric rheumatology. According to the ILAR criteria, the disease is defined by arthritis together with either a psoriatic rash or two of the following: dactylitis; nail pitting or onycholysis; psoriasis in a first-degree relative (20). Since the articular involvement generally occurs a few years before the development of skin manifestations, the diagnosis could be challenging. Articular involvement varies from symmetrical small-joint arthritis to asymmetrical lower-extremity large-joint arthritis and finally may progress to polyarthritis mimicking seropositive rheumatoid arthritis. Distal interphalangeal joint involvement typically suggests psoriatic arthritis. In general, arthritis of metacarpophalangeal, proximal interphalangeal and distal interphalangeal joints of one or more fingers forms the "sausage-like" fingers known as dactylitis (3,6,33). Features of ERA (enthesitis, sacroiliitis, spondylitis etc.) can be seen in some patients.

Typically, psoriatic plaques are seen on the extensor sides of joints, haired skin, the umbilicus and the perineum. Nail changes, including nail dystrophy, subungual hyperkeratosis and onycholysis are common among patients with psoriasis, 
albeit being less frequent in patients without arthritis $(3,20,33)$. Increased acute phase markers, anaemia of chronic disease and thrombocytosis could be seen. ANA is found in low or moderate titres in a significant proportion of patients. HLA B27 positivity accounts for $30 \%$ (33).

\section{Juvenile Idiopathic Arthritis and Uveitis}

Since uveitis represents one of the most severe extraarticular manifestations of JIA, regular screening by an experienced ophthalmologist is of crucial importance. The frequency of JIA-associated anterior non-granulomatous uveitis (iridocyclitis) is reported as being 15-67\% in various European regions (34). More attention should be paid to ANA-positive oligoarticular JIA female patients with early disease onset. Since these patients are at an especially high risk of uveitis, the ophthalmological examination should be performed every three months (6). The most frequently reported type of uveitis is chronic anterior uveitis (68.3\%), followed by acute anterior disease (16.2\%), recurrent anterior disease (12\%) and panuveitis (3.5\%). Among 1081 JIA cases, the uveitis percentage was reported as $13.1 \%$ (35). The onset of uveitis in oligoarticular JIA patients is often insidious and usually asymptomatic, although half of the children could have some symptoms related to uveitis (pain, redness, headache, photophobia, change in vision) (6). Patients with polyarticular JIA show no signs of ocular involvement at disease onset but $5-10 \%$ of them develop uveitis during the course of the disease (6). Acute, symptomatic uveitis is seen in $10-20 \%$ of ERA patients. Uveitis is characterized by attacks of unilateral or bilateral acute, painful, photophobic iritis and with hyperaemia of the sclera and conjunctiva. Patients with HLA B27 positivity are more prone to developing acute anterior uveitis $(6,34)$. Diagnosis and treatment delay lead to severe complications including band keratopathy, cataract, glaucoma or blindness. The frequency of blindness secondary to uveitis has markedly decreased due to new developments in diagnosis and treatment in recent studies $(34,35)$. Although the frequency of ANA positivity among patients with uveitis has been reported as being as high as $90 \%$ in countries of Western Europe, studies from Turkey showed its percentage to be lower (36). The initial treatment approach consists of local or systemic glucocorticoids. In order to avoid the adverse effects of glucocorticoids or, in unresponsive patients, different agents should be added to the therapy: methotrexate, azathioprine, mycophenolate mofetil and cyclosporine A. Biological agents are used in patients with resistant disease (infliximab, adalimumab, tocilizumab). Surgical interventions are reserved for patients with disease complications (37).

\section{Diagnosis and Disease Activity Measurements}

The diagnosis of JIA is based upon clinical criteria (Table 1). Occasionally, it can take time to establish the definitive diagnosis of the disease, due to the insidious course of the disease. Since there are no laboratory data specific for the disease, patients could be misdiagnosed at disease onset. Laboratory features are useful in differential diagnosis and in defining the disease subclassification (3).

The other relevant issue in the follow-up of JIA patients is the measurement of disease activity. Various measures are used in the assessment of disease activity (e.g. parent/patient visual analogue scale, physician visual analogue scale, number of active joints, anaemia, thrombocyte count, ESR, Steinbrocker score etc.) but none of them has been shown to be totally accurate. Many different instruments for measuring JIA disease activity have been established: Juvenile Arthritis Functional Assesment Report, Juvenile Arthritis Functional Assesment Scale, Juvenile Arthritis Disease Activity Score (JADAS). Furthermore, Childhood Health Assesment Questionnaire (CHAQ) and Paediatric Quality of Life Inventory were developed with the intention of incorporating estimates of physical, social and mental functioning into health assessment. Among numerous available instruments for JIA, CHAQ and JADAS are most widely used in routine practice. The American College of Rheumatology proposed measurements consisting of five items that are used in the assessment of disease activity in JIA patients (Table 2) (38-44).

\section{Treatment}

Chronic inflammation of the joints markedly limits the patient's functional ability and productivity in daily life. The underlying reason for the mentioned complications is the inflammation that is not under control. Other than joint-related complications, many other complications could develop in untreated patients, including growth retardation, uveitis, blindness and lifethreatening MAS. Adverse effects of drugs should be kept in mind as well (e.g. osteoporosis, growth retardation secondary to glucocorticoids etc.) (6). Thus, the JIA treatment should be prompt and effective. The importance of supportive measurements, such as adequate nutrition, calcium and Vitamin D supplements, should not be underestimated $(7,45,46)$. The aim of the therapy should be multidimensional: to control the pain, to preserve the range of motion/muscle strength/ muscle function, to induce disease remission, to manage systemic complications and to facilitate normal physical and psychosocial development. The duration of treatment should be adjusted every 3 months, until the goal of treatment is achieved. The disease activity should be regularly assessed (every 1-6 
months). Different instruments are used in disease activity assessment (Table 2). Disease activity indexes should be used in determining treatment goals. Additionally, compliance of the patient and parent, JIA subtype and treatment-related side effects should not be ignored in optimizing the best treatment target. Children and parents should be informed in detail about the process and goals (45).

Randomized controlled studies in paediatric rheumatology during the last 10-15 years have revealed the efficacy and safety of various agents. Table 3 shows the drugs commonly used in JIA treatment.

\section{NON-BIOLOGICAL MEDICAL TREATMENT}

\section{Non-Steroidal Anti-Inflammatory Drugs}

Non-steroidal anti-inflammatory drugs (NSAIDs) represent the traditional initial approach. Ibuprofen, indomethacin, tolmetin and naproxen are the most commonly used agents. This group of drugs is used particularly in children under 12 years old. In patients with oligoarticular JIA the disease remission could be induced by NSAIDs. The main characteristics of the drugs are their analgesic effect in lower doses and anti-inflammatory effect when used in higher doses. Treatment response is seen in the first 1-3 days with pain relief. This type of drug is considered tolerable in childhood patients, despite the abdominal pain and headache that could occasionally be seen as an adverse effect $(45,47)$.

\section{Corticosteroids}

This group of drugs is characterized by the most potent antiinflammatory activity. However, the usage is limited due to numerous side effects and low efficacy in the prevention of joint destruction. Intra-articular administration (methylprednisolone acetate, triamcinolone hexacetonide) has been shown to be effective in inducing remission in oligoarticular JIA patients, even with a single injection (48). Oral or parenteral administration of steroids has the ability to abate systemic symptoms in patients with the systemic form of the disease.

TABLE 2. Instruments for measurement of juvenile idiopathic arthritis disease activity routinely used in clinics for paediatric rheumatology (38-44)

\begin{tabular}{|c|c|}
\hline \multicolumn{2}{|l|}{ Paediatric response criteria } \\
\hline ACR Pedi 30, 50, 70, 90, 100 responses & $\begin{array}{l}\text { Improvement of } 30,50,70,90,100 \% \text {, respectively, compared to baseline values in at least three of the } 6 \text {-item set } \\
\text { accompanied with no worsening of } 30 \% \text { even in one item set }\end{array}$ \\
\hline ACR Pedi item set: & $\begin{array}{l}\text { 1. General evaluation of the disease efficiency, physician VAS } \\
(10 \mathrm{~cm} \text { visual analogue scale) } \\
\text { 2. General evaluation of the disease efficiency, parent/patient VAS } \\
(10 \mathrm{~cm} \text { visual analogue scale) } \\
\text { 3. Functional sufficiency-CHAQ } \\
\text { 4. Number of active joints } \\
\text { 5. Number of joints with limited motion } \\
\text { 6. Erythrocyte sedimentation rate }\end{array}$ \\
\hline JADAS & $\begin{array}{l}\text { 1. General evaluation of the disease efficiency, physician VAS } \\
(10 \mathrm{~cm} \text { visual analogue scale). } \\
\text { 2. General evaluation of the disease efficiency, parent/patient VAS } \\
(10 \mathrm{~cm} \text { visual analogue scale). } \\
\text { 3. Number of active joints } \\
\text { 4. ESR [0-10 scale by formula: }(\mathrm{ESH}-20) / 100] \\
\text { ESR values }<20 \mathrm{~mm} / \text { hour }=0, \text { ESR values }>120 \mathrm{~mm} / \text { hour }=120\end{array}$ \\
\hline Definitions of disease efficiency & 1. No active joint will be present \\
\hline $\begin{array}{l}\text { Clinically inactive disease } \\
\text { (all } 6 \text { sets should be met) }\end{array}$ & $\begin{array}{l}\text { 2. Fever, erythema, serositis, splenomegaly, diffuse lymphadenopathy will not be present } \\
\text { 3. No uveitis will be present } \\
\text { 4. ESR and CRP will be normal } \\
\text { 5. Morning stiffness will last less than } 15 \text { minutes } \\
\text { 6. Physician VAS will be the lowest value in the scale used }\end{array}$ \\
\hline Clinical remission with medication & Inactive disease for longer than 6 months under treatment \\
\hline Clinical remission without medication & Inactive disease for longer than 12 months after the end of treatment \\
\hline Quality of life measurement tools CHAQ & A disease-specific measurement tool that evaluates the ability to perform daily activities \\
\hline PedsQL & $\begin{array}{l}\text { Multidimensional child self-report and parent proxy-report scales (includes: physical health, emotional and social } \\
\text { functionality) (Lower scores denote a poorer quality of life) }\end{array}$ \\
\hline
\end{tabular}

ACR Pedi: American College of Pediatric Rheumatology; CRP: C-reactive protein; ESR: erythrocyte sedimentation rate; JADAS: Juvenile Arthritis Disease Activity Score; CHAQ:

Childhood Health Assessment Questionnaire; PedsQL: Pediatric Quality of Life Inventory; VAS: visual analog skala 
Symptoms such as joint pain, swelling, sensitivity or diseaserelated carditis, hepatitis, lung disease and fever show a significant response to steroid treatment. However, due to numerous side effects, usage in low doses or on alternative days is recommended in patients in whom control of the disease has been achieved. The generally used dose of steroids is up to 1 $\mathrm{mg} / \mathrm{kg} / \mathrm{day}$. The dose could be increased up to $1-2 \mathrm{mg} / \mathrm{kg} /$ day in patients with cardiac insufficiency or tamponade secondary to carditis or pericarditis. Patients with severe clinical presentation of systemic JIA should be treated with a high dose of steroids $(30 \mathrm{mg} / \mathrm{kg} /$ day) for three consecutive days $(45,47)$.

\section{DISEASE MODIFYING ANTI-RHEUMATIC DRUGS}

\section{Methotrexate}

Methotrexate is a folate antagonist, proven to be quite an effective and safe drug with long-lasting activity. The recommended treatment dose is $10-15 \mathrm{mg} / \mathrm{m}^{2} /$ week or $0.5-1 \mathrm{mg} /$ $\mathrm{kg} /$ week. Most patients show a response in the first 2-3 weeks of treatment. Occasionally, it can take some time to achieve treatment response. Folic acid or folinic acid at a dose of $1 \mathrm{mg} /$ $\mathrm{kg} /$ day is used in order to reduce the adverse effects including bone marrow suppression, nausea, oral ulcerations and hair loss. The fact that folinic acid decreases the methotrexate activity should not be forgotten $(6,45)$.

\section{Sulphasalazine}

Different studies have reported the efficiency of sulphasalazine in patients with JIA, especially in the oligoarticularand enthesitis-related forms of the disease. Treatment response is achieved in 6-8 weeks of treatment, in general. Headache, rash, gastrointestinal toxicity, myelosuppression, hypogammaglobulinaemia and allergic reactions are some of the possible adverse effects. The initial dose is $10-20 \mathrm{mg} / \mathrm{kg} /$ day, gradually increasing to $50 \mathrm{mg} / \mathrm{kg} /$ day in the following few weeks $(6,49)$.

\section{Other DMARDs Used in JIA}

Leflunomide is a pyrimidine synthesis inhibitor used in cases of methotrexate intolerance. Previous studies showed leflunomide to be equivalent to methotrexate in JIA treatment (50). Cyclosporine-A is the calcineurin inhibitor commonly used in patients with systemic JIA-associated MAS. It has no effect on joint damage (47).

\section{Biological treatment}

The advance in biologic therapeutics over the past 15 years has led to marked improvement in JIA treatment. In the biological era, the rate of joint damage decreased, and achieved disease remission increased with an increased number of patients

TABLE 3. Drugs used in treatment of juvenile idiopathic arthritis $(1,5,45)$

\begin{tabular}{|c|c|c|}
\hline Drugs & Mechanism & Dose \\
\hline \multicolumn{3}{|c|}{ Biologic DMARDs } \\
\hline Etanercept & TNF suppression, fusion protein TNF receptor suppression & $\begin{array}{l}0.8 \mathrm{mg} / \mathrm{kg} / \text { week or two times a week } \\
0.4 \mathrm{mg} / \mathrm{kg} \text { (maximum } 50 \mathrm{mg} / \text { week) }\end{array}$ \\
\hline Infliximab & TNF suppression, anti-TNF monoclonal chimeric antibody & $5-10 \mathrm{mg} / \mathrm{kg} / \mathrm{month}$ (maximum $200 \mathrm{mg} / \mathrm{month}$ ) \\
\hline Adalimumab & TNF suppression, anti-TNF monoclonal antibody & $\begin{array}{l}<30 \mathrm{~kg}: 20 \mathrm{mg} / \text { every } 2 \text { weeks }\left(24 \mathrm{mg} / \mathrm{m}^{2}\right) \\
>30 \mathrm{~kg}: 40 \mathrm{mg} / \text { every } 2 \text { weeks }\end{array}$ \\
\hline Anakinra & IL-1 receptor antagonist & 2-10 mg/kg/day (maximum 200 mg/day) \\
\hline Canakinumab & IL-1 inhibitor, anti-IL-1 $\beta$ monoclonal antibody & $\begin{array}{l}<40 \mathrm{~kg}: \text { 4-6 mg/kg/4-8 weeks, } \\
>40 \mathrm{~kg}: 150-300 \mathrm{mg} / \text { dose } / 4-8 \text { weeks }\end{array}$ \\
\hline Rilonacept & IL-1 suppression; soluble fusion protein & $2.2-4.4 \mathrm{mg} / \mathrm{kg} /$ week \\
\hline Tocilizumab & IL-6 receptor antagonist & $\begin{array}{l}\leq 30 \mathrm{~kg}, 12 \mathrm{mg} / \mathrm{kg} / 2-4 \text { weeks, } \geq 30 \mathrm{~kg} \\
8 \mathrm{mg} / \mathrm{kg} / 2-4 \text { weeks (maximum dose } 400 \mathrm{mg} \text { ) }\end{array}$ \\
\hline Abatacept & T-cell co-stimulator; soluble fusion protein & $10 \mathrm{mg} / \mathrm{kg} / 4$ weeks (maximum dose $500 \mathrm{mg}$ ) \\
\hline Rituximab & CD20 antigen suppression & $375 \mathrm{mg} / \mathrm{m}^{2} /$ weeks, for 4 weeks (maximum dose $500 \mathrm{mg}$ ) \\
\hline \multicolumn{3}{|c|}{ Non-biologic DMARDs } \\
\hline Methotrexate & Folate antagonist & $0.3-1 \mathrm{mg} / \mathrm{kg} /$ week (maximum $25 \mathrm{mg} /$ week \\
\hline Sulphasalazine & Inhibits dihydropteroate synthase & 12.5-50 mg/kg/day (maximum $2000 \mathrm{mg}$ ) \\
\hline Leflunomide & Inhibits dihydroorotate dehydrogenase & $<40 \mathrm{~kg}: 10 \mathrm{mg},>40 \mathrm{~kg}: 20 \mathrm{mg} /$ days \\
\hline Cyclosporine-A & Inhibits calcineurin & $3-5 \mathrm{mg} / \mathrm{kg} /$ day \\
\hline
\end{tabular}


with inactive disease. Despite the promising results of these medications, the blockade of important immunological pathways necessitates detailed safety monitoring. However, previous studies reported the safety of biological agents. The efficacy and safety of the biological agents used in JIA treatment are explained in the following text.

Etanercept: Etanercept is a fusion protein that binds to soluble TNF $\alpha$, decreasing downstream TNF receptormediated signlaling. Etanercept is a biological agent with relevant efficacy in the treatment of peripheral arthritis. It has proved to be the most efficient treatment option in polyarticular JIA patients. The dose of the drug is $0.8 \mathrm{mg} / \mathrm{kg} /$ week. The efficacy of etanercept becomes more prominent after the second or third dose (45,51). The most common adverse effect is the local reaction at the site of injection. Thus, the drug should be administered to different parts of the body. Recurrent upper respiratory tract infections are less frequent while severe infections requiring hospitalization are extremely rare $(52,53)$.

Infliximab: Infliximab is a chimeric monoclonal antibody that has a high affinity for $\mathrm{TNF} \alpha$. Unlike etanercept, infliximab binds to both soluble and membrane-bound TNF $\alpha$. Its efficacy in JIA therapy has been shown previously. The dose in usage is 3-6 mg/kg/4-8 weeks (maximum dose $200 \mathrm{mg}$ ). Spondyloarthropathies, inflammatory bowel disease, psoriatic arthritis and uveitis show a particularly excellent response to infliximab treatment $(37,45,54)$. Combined use of infliximab with methotrexate markedly increases drug efficiency. Apart from mild upper respiratory system infections, the frequency of severe and opportunistic infections is unremarkable. Compared to other TNF antagonists, allergic reactions during i.v. infusion appear to be more common $(45,53)$.

Adalimumab: Adalimumab is a fully humanized monoclonal antibody that binds to TNF $\alpha$. The usual dose is $24 \mathrm{mg} / \mathrm{m}^{2} / 15$ days (maximum $40 \mathrm{mg}$ ). Combined usage of adalimumab with methotrexate enhances the drug activity. It has been shown to be an efficient and safe drug as a first or second line of JIA therapy $(1,55)$.

Anakinra: Anakinra is a recombinant human IL-1 receptor antagonist. It is administered subcutaneously in doses of 2-10 $\mathrm{mg} / \mathrm{kg}$ /day (maximum $200 \mathrm{mg}$ ). Since IL-1 plays an important role in the pathogenesis of sJIA, multicentric studies showed the efficacy and safety of anakinra in sJIA treatment (56). Occasionally, injection pain and local injection site reactions make its usage difficult. In general, it is a well-tolerated drug with severe infections seen rarely $(45,52)$.

Canakinumab: Canakinumab is a fully humanized monoclonal antibody that binds specifically to IL-1 $\beta$. A multicentric study reported its efficacy in patients with systemic JIA (57). The recommended dose is $4 \mathrm{mg} / \mathrm{kg} /$ every 4-8 weeks for children under $40 \mathrm{~kg}$ in weight and $150 \mathrm{mg}$ every 4-8 weeks for children above $40 \mathrm{~kg}$. Canakinumab is used in many auto-inflammatory conditions. Due to a longer half-life and less frequent local reactions at the injection site compared to anakinra, it is commonly chosen as a first-line therapy by clinicians (45). Previous studies reported a slightly higher frequency of infections in treated patients, compared to placebo (52).

Tocilizumab: Tocilizumab is a recombinant, humanized monoclonal antibody that binds to the IL-6 receptor. It has been commonly used in active sJIA patients older than two, alone or in combination with methotrexate. The recommended dosage is $12 \mathrm{mg} / \mathrm{kg} / 2-4$ weeks below $12 \mathrm{~kg}$ and $8 \mathrm{mg} / \mathrm{kg} / 2-4$ weeks above $12 \mathrm{~kg}$. Tocilizumab is used in the treatment of unresponsive systemic JIA patients, particularly in those with active arthritis that show no improvement and in polyarticular JIA patients $(45,58)$. Double-blind, placebo-controlled studies with tocilizumab showed no significant increase in infections and no cases of tuberculosis or other opportunistic infections. It is important to mention that some infections could remain unrecognized in patients under tocilizumab treatment, due to its ability to decrease acute-phase markers and to inhibit fever reactions $(45,52)$.

Abatacept: Abatacept is a recombinant fusion protein that downregulates T-cell stimulation, leading to decreased B-cell and macrophage activation. The drug is used as monthly injections at a dose of $10 \mathrm{mg} / \mathrm{kg}$. Its efficiency and safety in patients with polyarticular JIA has been reported in previous studies. Unresponsiveness to other anti-TNF agents is an indication for abatacept. Except for mild infections requiring no hospital treatment, severe opportunistic infections have not been documented in patients treated with this drug $(45,52,59)$.

Rituximab: Rituximab is a human monoclonal antibody that increases B-cell apoptosis and decreases mature B-cells carrying CD20. Since B-cells represent its main target, it is shown to be eficient in all conditions related to $\mathrm{B}$ lymphocytes. The proposed dose of this drug is $375 \mathrm{mg} / \mathrm{m}^{2}$ for three or four doses. Rituximab has been used in paediatric lupus erythematosus patients as off-label. Data on the administration of rituximab in JIA patients are limited. There is a study reporting its efficacy in JIA (60). Vaccination for encapsulated bacteria is mandatory prior to treatment with rituximab $(45,60)$.

Tofacitinib/CP-690.550: Tofacitinib/CP-690.550 is a selective JAK inhibitor that acts by inhibiting JAK 1, JAK 2 and STAT 1. Currently, tofacitinib is used in the treatment of adult RA. There is an ongoing open-labelled study on tofacitinib in JIA treatment (45). 


\section{Prognosis}

Novel biological therapeutics, early aggressive treatment and effective intra-articular administration of steroids have led to marked improvement in the prognosis of JIA. Despite this progress, some patients still have an active disease with a progressive clinical course. Although the majority of oligoarticular JIA patients achieve remission, some of them still do not resolve totally $(5,26)$. The risk of uveitis, joint erosions with the development of severe sequelae and extension of the disease to polyarticular disease makes oligoarticular JIA an entity that requires careful monitoring with a need for aggressive, early treatment in cases of higher risk. A family history of the disease, early ankle and hip joint involvement and a higher number of affected joints at disease onset are indicators of poor prognosis in ERA patients (13). Systemic JIA has various prognoses with the majority of patients having a monocyclic disease course. However, articular involvement in sJIA patients usually persists. The remission rate markedly increases and the rate of joint damage decreases along with biological treatment (19). The response to biological treatment is lower in patients with psoriatic arthritis compared to other JIA subtypes (61). The percentage of achieved remission status among patients with RF-positive and RF-negative polyarticular JIA and extended oligoarticular JIA was found to be similar in patients under biological treatment, particularly etanercept. Biological agents have been shown to be efficient and safe in JIA patients, despite reports of increased frequency of infections that sometimes require hospitalization and sporadic reports of autoimmune diseases. There is some evidence that treatment with TNF blockers could increase the risk of malignancy in children. However, a clear causal relationship has not been established since underlying illnesses and the use of concomitant immunosuppressants bear a risk of malignancy as well (62). Frequent depression, sleep disturbance, anxiety and fatigue are reported more commonly among JIA patients than in healthy controls (42). Therefore, psychosocial monitoring could improve the success of treatment. JIA patients are more prone to cardiovascular disease than healthy controls (63). Routine echocardiographic screening improves the disease prognosis.

\section{CONCLUSION}

JIA is a heterogeneous disease group with many controversies regarding treatment options and clinical course. Since diagnosis and treatment delay can lead to irreversible damage, early recognition and adequate, timely treatment are of crucial importance. Disease activity measurements are important tools in terms of treatment success and follow-up. Occasionally, the treatment should be personalized with the protection of general treatment principles. A multidisciplinary approach is important in order to avoid the adverse effects of the drugs. The main goal of the treatment is to prevent possible disease-related complications and to enable patients to live a healthy life.

Conflict of Interest: No conflict of interest was declared by the authors.

\section{REFERENCES}

1. Giancane G, Consolaro A, Lanni S, Davi S, Schiappapietra B, Ravelli A. Juvenile Idiopathic Arthritis: Diagnosis and Treatment. Rheumatol Ther 2016;3:187-207.

2. Aslan M, Kasapcopur O, Yasar H, Polat E, Saribas S, Cakan H, et al. Do infections trigger juvenile idiopathic arthritis? Rheumatol Int 2011;31:215-20.

3. Ross E. Petty RML, Lucy R. Wedderburn. Juvenile Idiopathic Arthritis. In: Petty RE, Laxer RM, Lindsley CB, Wedderburn LR, eds. Textbook of Pediatric Rheumatology: Elsevier Saunders Company; 2016:188-284.

4. Petty RE, Southwood TR, Manners P, Baum J, Glass DN, Goldenberg J, et al. International League of Associations for Rheumatology classification of juvenile idiopathic arthritis: second revision, Edmonton, 2001. J Rheumatol 2004;31:390-2.

5. Gowdie PJ, Tse SM. Juvenile idiopathic arthritis. Pediatr Clin North Am 2012;59:301-27.

6. Weiss JE, Ilowite NT. Juvenile idiopathic arthritis. Pediatr Clin North Am 2005;52:413-42.

7. Prakken B, Albani S, Martini A. Juvenile idiopathic arthritis. Lancet 2011;377:2138-49.

8. Ozen S, Karaaslan Y, Ozdemir O, Saatci U, Bakkaloglu A, Koroglu E, et al. Prevalence of juvenile chronic arthritis and familial Mediterranean fever in Turkey: a field study. J Rheumatol 1998;25:2445-9.

9. Manners PJ, Diepeveen DA. Prevalence of juvenile chronic arthritis in a population of 12-year-old children in urban Australia. Pediatrics 1996;98:84-90.

10. Verwoerd A, Ter Haar NM, de Roock S, Vastert SJ, Bogaert D. The human microbiome and juvenile idiopathic arthritis. Pediatr Rheumatol Online J 2016;14:55.

11. Prahalad S, Shear ES, Thompson SD, Giannini EH, Glass DN. Increased prevalence of familial autoimmunity in simplex and multiplex families with juvenile rheumatoid arthritis. Arthritis Rheum 2002;46:1851-6.

12. AdrovicA, BarutK, Sahin S, Kasapcopur O. Juvenile Spondyloarthropathies. Curr Rheumatol Rep 2016;18:55.

13. Aggarwal A, Misra DP. Enthesitis-related arthritis. Clin Rheumatol 2015;34:1839-46.

14. Ferucci ED, Majka DS, Parrish LA, Moroldo MB, Ryan M, Passo M, et al. Antibodies against cyclic citrullinated peptide are associated with HLADR4 in simplex and multiplex polyarticular-onset juvenile rheumatoid arthritis. Arthritis Rheum 2005;52:239-46.

15. Hinks A, Bowes J, Cobb J, Ainsworth HC, Marion MC, Comeau ME, et al. Fine-mapping the MHC locus in juvenile idiopathic arthritis (JIA) reveals genetic heterogeneity corresponding to distinct adult inflammatory arthritic diseases. Ann Rheum Dis 2016 [Epub ahead of print].

16. Gonzalez B, Larrañaga C, León O, Díaz P, Miranda M, Barría M, et al. Parvovirus B19 may have a role in the pathogenesis of juvenile idiopathic arthritis. J Rheumatol 2007;34:1336-40.

17. Zhou J, Ding Y, Zhang Y, Feng Y, Tang X, Zhao X. CD3+CD56+ natural killer $\mathrm{T}$ cell activity in children with different forms of juvenile idiopathic arthritis and the influence of etanercept treatment on polyarticular subgroup. Clin Immunol 2016;176:1-11 [Epub ahead of print]. 
18. Kumar S. Systemic Juvenile Idiopathic Arthritis: Diagnosis and Management Indian J Pediatr 2016;83:322-7.

19. Cimaz R. Systemic-onset juvenile idiopathic arthritis. Autoimmun Rev 2016;15:931-4.

20. Ravelli A, Martini A. Juvenile idiopathic arthritis. Lancet 2007;369:76778.

21. Barut K, Yücel G, Sinoplu AB, Şahin S, Adroviç A, Kasapçopur Ö. Evaluation of macrophage activation syndrome associated with systemic juvenile idiopathic arthritis: single center experience over a one-year period. Turk Pediatri Ars 2015;50:206-10.

22. Ravelli A, Minoia F, Davi S, Horne A, Bovis F, Pistorio A, et al. 2016 Classification Criteria for Macrophage Activation Syndrome Complicating Systemic Juvenile Idiopathic Arthritis: A European League Against Rheumatism/American College of Rheumatology/Paediatric Rheumatology International Trials Organisation Collaborative Initiative. Ann Rheum Dis 2016;75:481-9.

23. Sahin S, Adrovic A, Barut K, Kasapcopur O. Systemic-onset juvenile idiopathic arthritis or incomplete Kawasaki disease: a diagnostic challenge. Clin Exp Rheumatol 2016 [Epub ahead of print].

24. Rosenberg AM. Uveitis associated with childhood rheumatic diseases. Curr Opin Rheumatol 2002;14:542-7.

25. Ogdie A, Weiss P. The Epidemiology of Psoriatic Arthritis. Rheum Dis Clin North Am 2015;41:545-68.

26. Guillaume S, Prieur AM, Coste J, Job-Deslandre C. Long-term outcome and prognosis in oligoarticular-onset juvenile idiopathic arthritis. Arthritis Rheum 2000;43:1858-65.

27. Al-Matar MJ, Petty RE, Tucker LB, Malleson PN, Schroeder ML, Cabral DA. The early pattern of joint involvement predicts disease progression in children with oligoarticular (pauciarticular) juvenile rheumatoid arthritis. Arthritis Rheum 2002;46:2708-15.

28. Demirkaya E, Ozen S, Bilginer Y, Ayaz NA, Makay BB, Unsal E, et al. The distribution of juvenile idiopathic arthritis in the eastern Mediterranean: results from the registry of the Turkish Paediatric Rheumatology Association. Clin Exp Rheumatol 2011;29:111-6.

29. Abramowicz S, Kim S, Prahalad S, Chouinard AF, Kaban LB. Juvenile arthritis: current concepts in terminology, etiopathogenesis, diagnosis, and management. Int J Oral Maxillofac Surg 2016;45:801-12.

30. Gurcay E, Eksioglu E, Yuzer S, Bal A, Cakci A. Articular damage in adults with juvenile idiopathic arthritis. Rheumatol Int 2009;29:635-40.

31. Kasapçopur O, Altun S, Aslan M, Karaarslan S, Kamburoglu-Göksel A, Saribas S, et al. Diagnostic accuracy of anti-cyclic citrullinated peptide antibodies in juvenile idiopathic arthritis. Ann Rheum Dis 2004;63:1687-9.

32. Weiss PF, Klink AJ, Behrens EM, Sherry DD, Finkel TH, Feudtner C, et al. Enthesitis in an inception cohort of enthesitis-related arthritis. Arthritis Care Res (Hoboken) 2011;63:1307-12.

33. Ravelli A, Consolaro A, Schiappapietra B, Martini A. The conundrum of juvenile psoriatic arthritis. Clin Exp Rheumatol 2015;33:40-3.

34. Clarke SL, Sen ES, Ramanan AV. Juvenile idiopathic arthritis-associated uveitis. Pediatr Rheumatol Online J 2016;14:27.

35. Sabri K, Saurenmann RK, Silverman ED, Levin AV. Course, complications, and outcome of juvenile arthritis-related uveitis. J AAPOS 2008;12:53945.

36. Kasapçopur O, Yologlu N, Ozyazgan Y, Ercan G, Caliskan S, Sever L, et al. Uveitis and anti nuclear antibody positivity in children with juvenile idiopathic arthritis. Indian Pediatr 2004;41:1035-9.

37. Oray M, Tuğal-Tutkun İ. Treatment of Juvenile Idiopathic ArthritisAssociated Uveitis. Turk J Ophthalmol 2016;46:77-82.

38. Ringold S, Wallace CA. Measuring clinical response and remission in juvenile idiopathic arthritis. Curr Opin Rheumatol 2007;19:471-6.

39. Wallace CA, Huang B, Bandeira M, Ravelli A, Giannini EH. Patterns of clinical remission in select categories of juvenile idiopathic arthritis. Arthritis Rheum 2005;52:3554-62.
40. Consolaro A, Giancane G, Schiappapietra B, Davì S, Calandra S, Lanni $\mathrm{S}$, et al. Clinical outcome measures in juvenile idiopathic arthritis. Pediatr Rheumatol Online J 2016;14:23.

41. Backström M, Tynjälä P, Ylijoki H, Aalto K, Kärki J, Pohjankoski H, et al. Finding specific 10-joint Juvenile Arthritis Disease Activity Score (JADAS10) and clinical JADAS10 cut-off values for disease activity levels in non-systemic juvenile idiopathic arthritis: a Finnish multicentre study. Rheumatology (Oxford) 2016;55:615-23.

42. Butbul Aviel Y, Stremler R, Benseler SM, Cameron B, Laxer RM, Ota S, et al. Sleep and fatigue and the relationship to pain, disease activity and quality of life in juvenile idiopathic arthritis and juvenile dermatomyositis. Rheumatology (Oxford) 2011;50:2051-60.

43. Tarakci E, Yeldan I, Kaya Mutlu E, Baydogan SN, Kasapcopur O. The relationship between physical activity level, anxiety, depression, and functional ability in children and adolescents with juvenile idiopathic arthritis. Clin Rheumatol 2011;30:1415-20.

44. Wallace CA, Giannini EH, Huang B, Itert L, Ruperto N. American College of Rheumatology provisional criteria for defining clinical inactive disease in select categories of juvenile idiopathic arthritis. Arthritis Care Res (Hoboken) 2011;63:929-36.

45. Kasapçopur Ö, Barut K. Treatment in juvenile rheumatoid arthritis and new treatment options. Turk Pediatri Ars 2015;50:1-10.

46. Dağdeviren-Çakır A, Arvas A, Barut K, Gür E, Kasapçopur Ö. Serum vitamin $\mathrm{D}$ levels during activation and remission periods of patients with juvenile idiopathic arthritis and familial Mediterranean fever. Turk $\mathbf{J}$ Pediatr 2016;58:125-31.

47. Makay B, Unsal E, Kasapcopur O. Juvenile idiopathic arthritis. WJR. World. 2013;3:16-24.

48. Ravelli A, Lattanzi B, Consolaro A, Martini A. Glucocorticoids in paediatric rheumatology. Clin Exp Rheumatol 2011;29(5 Suppl 68):14852.

49. Hügle B, Horneff G. The role of synthetic drugs in the biologic era: therapeutic strategies for treating juvenile idiopathic arthritis. Expert Opin Pharmacother 2016;17:703-14.

50. Silverman E, Mouy R, Spiegel L, Jung LK, Saurenmann RK, Lahdenne $\mathrm{P}$, et al. Leflunomide or methotrexate for juvenile rheumatoid arthritis. $\mathrm{N}$ Engl J Med 2005;352:1655-66.

51. Otten MH, Prince FH, Armbrust W, ten Cate R, Hoppenreijs EP, Twilt M, et al. Factors associated with treatment response to etanercept in juvenile idiopathic arthritis. JAMA 2011;306:2340-7.

52. Horneff G. Biologic-associated infections in pediatric rheumatology. Curr Rheumatol Rep 2015;17:66.

53. Kilic O, Kasapcopur O, Camcioglu Y, Cokugras H, Arisoy N, Akcakaya $\mathrm{N}$. Is it safe to use anti-TNF- $\alpha$ agents for tuberculosis in children suffering with chronic rheumatic disease? Rheumatol Int 2012;32:2675-9.

54. Katsicas MM, Russo R. Biologic agents in juvenile spondyloarthropathies. Pediatr Rheumatol Online J 2016;14:17.

55. Schmeling H, Minden K, Foeldvari I, Ganser G, Hospach T, Horneff G. Efficacy and safety of adalimumab as the first and second biologic agent in juvenile idiopathic arthritis: the German Biologics JIA Registry. Arthritis Rheumatol 2014;66:2580-9.

56. Quartier P, Allantaz F, Cimaz R, Pillet P, Messiaen C, Bardin C, et al. A multicentre, randomised, double-blind, placebo-controlled trial with the interleukin-1 receptor antagonist anakinra in patients with systemic-onset juvenile idiopathic arthritis (ANAJIS trial). Ann Rheum Dis 2011;70:74754.

57. Ruperto N, Brunner HI, Quartier P, Constantin T, Wulffraat N, Horneff G, et al. Two randomized trials of canakinumab in systemic juvenile idiopathic arthritis. N Engl J Med 2012;367:2396-406.

58. De Benedetti F, Brunner HI, Ruperto N, Kenwright A, Wright S, Calvo I, et al. Randomized trial of tocilizumab in systemic juvenile idiopathic arthritis. N Engl J Med 2012;367:2385-95. 
59. Ruperto N, Lovell DJ, Quartier P, Paz E, Rubio-Pérez N, Silva CA, et al. Long-term safety and efficacy of abatacept in children with juvenile idiopathic arthritis. Arthritis Rheum 2010;62:1792802.

60. Alexeeva EI, Valieva SI, Bzarova TM, Semikina EL, Isaeva KB, Lisitsyn $\mathrm{AO}$, et al. Efficacy and safety of repeat courses of rituximab treatment in patients with severe refractory juvenile idiopathic arthritis. Clin Rheumatol 2011;30:1163-72.
61. Davies R, Gaynor D, Hyrich KL, Pain CE. Efficacy of biologic therapy across individual juvenile idiopathic arthritis subtypes: A systematic review. Semin Arthritis Rheum 2016. [Epub ahead of print]

62. Diak P, Siegel J, La Grenade L, Choi L, Lemery S, McMahon A. Tumor necrosis factor alpha blockers and malignancy in children: forty-eight cases reported to the Food and Drug Administration. Arthritis Rheum 2010;62:2517-24.

63. Koca B, Sahin S, Adrovic A, Barut K, Kasapcopur O. Cardiac involvement in juvenile idiopathic arthritis. Rheumatol Int 2017;37:137-142. 